\title{
Integrating Sustainability into Construction Education
}

\author{
Ms. Jamie R. Metzinger, Purdue University
}

Construction Management PhD Student at Purdue University

Dr. Jessica Anderson Cabral, Purdue University

Prof. Bradley Louis Benhart, Purdue University

Brad Benhart has been a mainstay in the construction industry for over 25 years. He has been involved in all aspects of construction including: healthcare, commercial, residential, international, and all related aspects of training and education. In 2009, Benhart furthered his commitment and passion to construction education by accepting a professorship at Purdue University in their School of Construction Management. Brad focuses on construction supervision, project management, strategic planning, preconstruction, and sustaining the built environment. At Purdue, Benhart also leads the Healthcare Construction Management program and works with the first ASHE (American Society of Healthcare Engineering) student chapter. His position allows him to further develop construction education in the built environment and be an industry advocate for the next generation of builders. He is also very involved in field supervision training programs, both at Purdue and on the national level. He focuses on the sustainability of our industry by mentoring the retiring baby boomers with new foremen and superintendents. Benhart also has an extensive resume in industry. His previous position was Vice President with Pepper Construction Company of Chicago, IL. While at Pepper, Brad managed multiple projects ranging from $\$ 100 \mathrm{k}$ to $\$ 250$ million dollars. He continues to be an adjunct professor at Northwestern University in project management and has actively taught and trained many employees in the industry. When he is not in the classroom, Brad owns Integrated Construction Resources, a construction consulting company that focuses on strategic planning, training, expert witness analysis, and owners' representation. In his free time, he enjoys traveling with his family.

\section{Ms. Patti Morgan, Purdue University \\ Mr. Scott Douglas Santon, Purdue University}




\title{
Integrating Sustainability into Construction Education
}

\begin{abstract}
The demand for sustainable development and construction has become increasingly popular over the years. New data is constantly emerging about the sources and effects to the built environment and society from construction related activities and the most cost effective manner in which to address them. A compounding issue related to sustainability is the fact there is no definitive right or wrong answer. Critical thinking, information analysis, and interdisciplinary collaboration are all vital to developing the best solution for sustainable development. Education is the cornerstone of this process. Continuing education will always be necessary; however, an initial fundamental understanding of sustainable concepts is needed in order to construct more knowledge. The most opportune time for future industry leaders to establish these concepts is in parallel of other construction fundamentals in higher education. While many construction education programs have successful history with construction fundamentals, they have not yet fully integrated sustainable education. This paper addresses sustainable construction student objectives, strategies for implementing sustainable education, and challenges and successes other institutions have encountered. Research has shown that full implementation, rather than isolated sustainable courses, has the most impact for students. A well-developed plan accounting for faculty support, active learning, and development of "soft" skills is vital to successful implementation.
\end{abstract}

\section{Introduction}

Although the terms "sustainable / sustainability" and "sustainable development" are not new concepts, their definition, applications and implementation have been highly debated and modified over the years, especially in the construction industry. New data is constantly being learned about the sources and effects to the built environment and society from construction related activities and the most labor, material, and cost effective manner in which to address them. Compounding issues related to sustainability is the fact that there is no definitive right or wrong answer; critical thinking, information analysis, and interdisciplinary collaboration is vital to developing the best solution for sustainable development. Education is the cornerstone of this process. Continuing education will always be necessary; however, a fundamental understanding of sustainable concepts is first needed in order to construct more knowledge. The most opportune time for new industry leaders to establish these concepts is in parallel of other construction fundamentals in higher education. This review of literature evaluates previous research and case studies that implemented sustainable education into their program in order to apply these principles to construction education. The literature included relates to the origins of sustainable learning as well as research and case studies of initial implementation of sustainable education.

Globally, the United Nations (UN) has led the initiative for sustainable development, holding summits with national leaders in an effort to increase awareness and effective action. Many of the initiatives that various organizations use employ the intrinsic notion of sustainability from the UN. In 1987, the United Nations World Commission on Environment and 
Development (WCED) published Our Common Future, also known as the Brundtland Report, in order to create a strategy that can be used for sustainable development. The report states that "Humanity has the ability to make development sustainable to ensure that it meets the needs of the present without compromising the ability of future generations to meet their own needs" (WCED, 1987, p 16); thus providing a definition of sustainability and sustainable development. However, as this is a loosely defined end goal, there are many paths of execution to sustainable development and differing opinions of the best approach. Further, there is not always a consensus on which resources are being compromised and if they are truly necessary. Three pillars of sustainability were developed to include economy, environment, and society (Eladaway, Pierrakos, \& Truax, 2015, Chau, 2007, Tsai, 2013), still it is difficult to execute all three pillars as many people tend to focus on only one or two.

A few years later, 1992, in Rio de Janeiro, Brazil, the United Nations Conference on Environment and Development met again for the Earth Summit. From this, Agenda 21 was created as a voluntary agreement as an implementation strategy for sustainable development, which the President of United States, George Bush, did sign. Chapter 36 of this document deals with promoting sustainable education. Educational objectives were developed that encompass reorienting education towards sustainability, improve universal access to basic education from children to adults, and achieving environmental and development awareness throughout society (WCED, 1992). This is even more relevant to construction education because of the impact of the construction process on the surrounding environment (Brncich, Shane, Strong, \& Passe, 2011) and the wide range of disciplines that are involved in order to connect several fields of knowledge (Soria, Bella, Hernández, Suñén, \& Díaz, Juan, 2013). Further, the performance of a building is important as people spend a majority of their time in a building, which in turn impacts that environment as well. Indeed, sustainability is an essential aspect of construction, but consistent integration into construction education has yet to be achieved.

According to Lozano, et al., (2015), generally speaking, sustainable development education (SDE) has not been holistically implemented throughout higher education institutions (HEIs) but compartmentalized. Improved integration occurs when the entire HEI is committed to SDE. Furthermore, traditional pedagogy has resulted in passive learning and a linear process of problem solving. HEIs are starting to recognize the downfall of this process and are shifting towards various aspects of problem/project based learning (PBL) in order to actively engage students in learning and allow them to apply and understand information as opposed to only finding an answer (El-adaway et al., 2015). Project based learning is further applicable to construction education as no jobsite is exactly the same and issues that arise do not always have one right answer which therefore requires advanced critical thinking skills and the ability to collaborate with other disciplines in order to find the best possible solution for all parties involved.

Many construction education programs have an extensive, successful history, but have not yet fully integrated SDE. In order to achieve the most effective integration, a well-planned preparatory phase should first be completed (Verhulst \& Lambrechts, 2015). Our department's SDE includes an elective upper level course dedicated solely to sustainable projects (ranging from piezoelectric-power to clean air filters to tiny homes) and general inclusion throughout the curriculum. At this time there are no specific requirements per each course for SDE. However, 
our department is redesigning the entire curriculum towards a project-based curriculum, which opens the door to make a more concrete plan for SDE. In order to create this plan, this paper will address sustainable construction student objectives, strategies for implementing SDE, and challenges and successes other institutions have encountered.

\section{Student Learning Outcomes}

"Sustainable development of the world depends on the formation of persons of good morals and highly creative abilities capable of tackling complex problems of development taking into account long-term systemic effects" (Nasibulina, 2015, p. 1077). Thus, students should understand how their decisions and actions affect the environment and society (Lozano, Ceulemans, \& Scarff Seatter, 2015). The American Council for Construction Education (ACCE) only requires a basic understanding of sustainable construction education; however, various researchers have identified several skills and learning outcomes for construction SDE. These skills and outcomes are related to all facets of problem solving from soft or social skills in order to communicate and understand other disciplines and utilizing technical knowledge in order to develop the best possible result. "Social skills are central to the delivery of the solution while technical skills focus on problem solving" (Valdez-Vasquez \& Clevenger, 2015, p. 79). Many of these skills and objectives are already needed for construction professionals, but are broadened for sustainability due to the complex nature and open-endedness of sustainable issues.

Specifically related to sustainable development (SD), The United Nations Educational, Scientific and Cultural Organization provided 14 learning outcomes for all levels of ESD which lay the groundwork for several organizations' and institutions' learning objectives:

- Critical reflective thinking

- Understanding complexity/systemic thinking

- Futures thinking

- Planning and managing change

- Understanding inter-relationships across disciplines

- Applying learning in a variety of life-wide contexts

- Decision-making, including in uncertain situations

- Dealing with crises and risks

- Acting with responsibility locally and globally

- Ability to identify and clarify values

- Acting with respect for others

- Identifying stakeholders and their interests

- Participating in democratic decision-making

- Negotiating and consensus building (Wals, 2009, p. 49)

El-adaway et al. (2015), Chau (2007), and Yasin \& Rahman (2015) reiterate these objectives within their research and also add the ability to adapt to change, continuous learning. While technical knowledge is important, as these outcomes suggest, however, the ability to discern and apply knowledge is most important. 
In the past, design, construction, and even sub-construction activities were separate activities; however, collaboration and negotiation are now cornerstone elements of a successful construction professional, and even more so in dealing with sustainable development. These skills are now being formally demanded by the construction industry from higher education graduates. Collaboration requires an understanding of expectations, backgrounds, and capabilities of people with which one works (Valdez-Vasquez \& Clevenger, 2015, Brncich et al., 2011). Furthermore, when a team is truly working well together, "they are able to communicate... to ask critical questions, to challenge one's own and others behavior, to think in a holistic manner and to think about issues in the long term as well as being capable of taking action" (Sewilam, McCormack, Mader, \& Abdel Raouf, 2015, p. 224) which results in more effective solutions. Skills related to advanced collaboration include active listening, respect, manners, positive attitude, focus, social awareness, and communication. Unfortunately, these skills, as with other social skills, are not inherently learned and should be explicitly suggest by the instructor for group projects, instead of simply directing to "collaborate".

Communication is another key element for sustainable construction, both interpersonal and technical (Chau, 2007, Jawahir, Rouch, Dillon, Holloway, \& Hall, 2007). Improving one's emotional intelligence and active listening are important steps to further develop communication skills. Emotional intelligence is the ability to recognize and be aware of one's own and others' emotions. This is crucial during collaboration and negations as people can become passionate about their position in a situation and it is imperative to be able to recognize and deflate any potential anger or hostility. When a student can accomplish this, they can lead the team to social and cognitive processes that develop higher function problem solving (El-adaway et al., 2015). Technical and written communication is also important as construction managers are often the point of contact for several team members on the project. Using clear and appropriate technical language, especially in documentation, is needed for consistency and accuracy (Brncich et al., 2011). Being able to effectively communicate helps to build better professional relationships which in turn makes the entire construction process run more effectively.

It is essential that students analyze, comprehend, and understand the impact of the construction process and materials used along all three pillars of sustainability, economic, environment, and social. Understanding material life-cycle helps to make more sustainable material choices for the building. Life-cycle issues include energy and time consumption for development, production, and waste, as well material reuse and recycling (Jawahir et al., 2007). Students must also be able to recognize efficient and environmental construction processes. This includes reducing the use of land, water, and other natural resources (Sullivan \& Walters, 2013, Manoliadis, 2009) and preventing or reducing source pollution and environmental waste (Chau, 2007, Manoliadis, 2009). Students must be allowed to develop their own problem-solving and critical thinking skills in order to apply construction knowledge in a holistic, sustainable manner.

Summarizing and expanding upon the UN's learning outcomes, Lozano, Ceulemans, \& Scarff Seatter, (2015) developed four learning outcomes for SDE specifically related to corporate organizations:

1. Understand organizations, their elements, and their attitudes, and how they influence and contribute to sustainability; 
2. Understand the different types of change and how they can be managed in the corporate sustainability context;

3. Be able to recognize drivers, barriers to change, and strategies to overcome the barriers in a sustainability context within the organization; and

4. Critically reflect on and analyze organizations, in order to be able to implement change management for sustainability (p. 209).

Additionally, knowledge of environmental law, policies, and management is needed as well (Chau, 2007). These knowledge outcomes deal directly with holistic sustainable development; for construction management leaders, understanding how the construction process fits into these outcomes is crucial. Not only do construction operations affect the environment, but so do corporate operations (Lozano, Ceulemans, \& Scarff Seatter, 2015). Thus also understanding corporate sustainability and how actions across a company affects all aspects of sustainability is just as important. Comprehension of these processes places students in a position to make sustainable suggestions, as a result "helping them become more sustainability orientated, and improve their employability prospects" (Lozano, Ceulemans, \& Scarff Seatter, 2015, p. 209).

\section{SDE Integration Strategies}

It is important to have a successful SDE integration in order to best achieve these student learning outcome. According to Lozano, Ceulemans, \& Scarff Seatter's (2015) research, there are five main approaches to incorporate SDE:

1. Coverage of some environmental issues and material in an existing course or courses;

2. A specific SD course

3. SD intertwined as a concept in regular disciplinary courses, tailored to the nature of each specific course

4. SD as a possibility for specialization within the framework of each faculty and

5. SD as an undergraduate or post-graduate program (p. 206).

From these approaches, Ceulemans, Molderez, \& Van Liedekerke (2015) defined horizontal and vertical integration strategies. Horizontal integration involves incorporating sustainability concepts across several courses within a curriculum and vertical integration involves creation and addition of individual sustainability courses within a curriculum. Utilizing vertical integration and creating individual courses contribute to students learning isolated knowledge resulting in not being able to apply SD to needed situations (Lozano, Ceulemans, \& Scarff Seatter, 2015). However, utilizing horizontal integration into existing courses aids students in applying knowledge in a holistic manner across several disciplines (Ceulemans et al., 2015). Soria et al., (2013) suggest that a combination of both integration styles is most appropriate. Development of a preparatory course within the first year of classes will help to construct basic concepts and understanding of SD topics in which to build and apply critical thinking skills in a multidisciplinary setting in higher level courses. When utilizing this method, it is extremely important to ensure that horizontal integration is being incorporated in subsequent courses to reinforce the knowledge and skill learned and to avoid isolating knowledge. 
Student-centered, active learning pedagogies are perhaps the best approach within the classroom, not just for SDE, but for construction management in general. El-adaway et al. (2015) found that in active learning:

- Student autonomy and initiative are accepted and encouraged;

- The teacher asks open-ended questions and allows wait time for responses;

- Class activities are student centered, and students are encouraged to ask their own questions, carry out their own experiments, make their own analogies, and come to their own conclusions;

- Higher-level thinking is promoted through student close engagement in dialogue with the teacher and with each other as well as in learning experiences that challenge hypotheses and foster discussion;

- Classes can take unexpected turns as students are given the autonomy to direct their own explorations; and

- Encourage students to work together, to share ideas and information freely with each other, and to use modern instruments to extend their intellectual capabilities (pp 1-2).

PBL provides an environment in which students can engage in interdisciplinary active learning in real-world scenarios where information is often unnecessary, erroneous, missing, or delayed. This allows students to perform their own research and apply learned knowledge in order to become "experts" themselves instead of passively receiving knowledge from an expert (Dobson \& Tomkinson, 2012). Thus, the learning outcomes shift from general knowledge and memorization to developing analytical and critical thinking skills (Yasin \& Rahman, 2011) applicable to a wide range of complex, open-ended, real-life problems.

In the PBL process, the instructor identifies the issue or frames the context in order for students to identify the problem and provides foundation background information (Dobson \& Tomkinson, 2012). This information should provide students with a general understanding of construction practices in order to evaluate their impact to sustainability issues (Wang, 2009). The student groups then work together to identify and analyze data in order to apply information to develop an outcome that fits within the parameters established by the instructor (Dobson \& Tomkinson, 2012). This learning process most mimics the problem-solving process within the construction industry, as well as with SD, thus helping to prepare students even more effectively for professional industry.

Watson, Noyes, \& Rodgers (2013) found that the results of a self-assessment study suggest that some instructors believe they were including sustainability concepts, but upon review of course content, they were not. To avoid this when implementing SDE, identifying areas within the curriculum where integration can occur is key, for both horizontal and vertical integration and even within other subjects and specializations (Anand, Bisaillon, Webster, \& Amor, 2015). PBL will help to further ensure a deeper connection to SDE when groups are mentored by industry professionals from relevant fields (Anand et al., 2015, Wolcott et al., 2011) such as environmental engineering, architecture, urban planning (El-adaway et al., 2015). 
Part of the instructor role in active learning is to help students develop their own knowledge and independent critical thinking skills in order to become adaptable to various disciplines and situations as SD solutions cannot be solved within independent disciplines (Tsai, 2013). Hence, teams should be a mixture of students of varied backgrounds, even if within the same program; encouraging appreciation of the different viewpoints of other students and disciplines and the value and influence of their corresponding input. Additionally, through this process students should develop an understanding of how decisions influence the built environment (Wolcott et al., 2011, Sewilam et al., 2015). Construction professionals must make decisions based on their capability to weigh all options, analyze consequences and make the best possible solution (Manoliadis, 2009). Ultimately, the students must come to realize that due to the nature of the three pillars of sustainability, economics, environment, and society, and the interactions of amulti-disciplinary team, there will be competing goals on a project and they will have to utilize their knowledge to make the best SD decision.

\section{Challenges}

Across the world and across different disciplines, HEIs have started implementing SDE into their curriculum and researchers have identified some of the challenges of implementation. The challenges are related to logistics, students, and faculty. Perhaps the most critical factor is resistance from faculty and staff to change, which is directly linked to failure (Verhulst \& Lambrechts, 2015). Acknowledging these challenges ahead of time and developing a plan to prevent and overcome them will make the implementation process more efficient.

Organizational change can be difficult to implement regardless of the type of change or organization. As such, scholars have found that many of the limitations of SDE implementation are not necessarily unique to sustainability, but rather the organization's ability to execute the change. Providing proper resources and support to faculty and staff help to ease the incorporation of change (Verhulst \& Lambrechts, 2015). Lozano et al. (2015) found that although SDE for instructors is crucial for SDE into curriculum, there is a narrow utilization on staff training programs. These training programs should include integrated sustainable design practices, research basis for sustainable designs, models depicting how the current program can transition SDE into curriculum, (Wolcott et al., 2011) interdisciplinary integration (Brncich et al., 2011), and standard definitions and concepts of SDE. Other important resources include financial, data, staffing, and policy issues (Verhulst \& Lambrechts, 2015). Providing faculty with these resources will help to make them feel more knowledgeable in order to incorporate SDE. It is important to note that these resources must continue beyond the initial implementation and continue on in order to avoid not keeping up with industry trends (Wolcott et al., 2011) and demotivation (Verhulst \& Lambrechts, 2015).

Knowledge resources are needed for overcoming resistance from faculty and staff, however, identifying the human factors to change implementation is just as important. "People are particularly likely to resist change when they see it as threatening their interests and when they believe that their knowledge and skills may be made irrelevant as change takes place" (Verhulst \& Lambrechts, 2015, p. 192). Furthermore, resistance exists when there is a lack of interest or involvement which can be a result of lack of awareness of the relevance of SDE into 
curriculum and specific topics. Open, transparent lines of communication with faculty and allowing empowerment will help to overcome resistance.

Student resistance is not necessarily considered a direct factor to failure, but can have adverse effects. Most students are not used to inter-disciplinary critical thinking, ambiguous information, and open-ended questions. Further, the best application for SDE is team projectbased learning which is another structure that most students are not used to. In a newly designed course, El-adaway et al. (2015) found that in the beginning, students had a difficult time adapting to the new structure and actually considered dropping the course. Although the students did not drop, the stress and frustration of adjusting to a new class structure can distract from learning objectives.

\section{Successes}

Similar to the challenges of implementing SDE, successes relate to logistics and faculty. From an institutional standpoint, the most successful program implementation occurred when there was a strong commitment throughout the entire institution, providing strong resources and support. Identifying and utilizing human factors is another key to success of implementation; research found that initiatives from committed individuals or groups played an important role in starting up of research and education of SDE (Holmberg, Svanström, Peet, Mulder, Ferrer-Balas, \& Segalàs, 2008).

Institution-wide support of SD has shown to have positive influences in SDE. This includes both SD in campus operations and commitment to SDE. Incorporating SD for new infrastructure, such as requiring LEED certification for construction, and operations creates a sustainable built environment. Not only does this help to show students the institution's commitment to SD, but also provides a learning environment in which students can experience real-life SD scenarios (El-adaway et al., 2015). Developing student organizations help to further engage students, faculty, and staff from various disciplines together that might not otherwise meet within the classroom. Management commitment and crediting efforts within the organization is absolutely necessary, which includes enabling or facilitating SDE integration and maintaining a current SDE (Holmberg et al., 2008). Regional collaboration is also an important step for SDE. Showing that the institution is working with the local community shows a deeper commitment to SD and provides resources to students outside of the campus (Anand et al., 2015). Signing a declaration, charter, or initiative (DCIs) also helps to strengthen commitment to sustainability; more than 1000 university leaders across the world have signed various DCIs such as Rio +20 Higher Education Sustainability Initiative, Kyoto Declaration International Association of Universities, and COPERNICU University Charter (Lozano, Ceulemans, AlonsoAlmeida, et al., 2015). Legitimizing SDE through a visible commitment to SD develops a more profound awareness of the importance of SD for both students and instructors.

Studies have shown that the more people within an organization are involved, the better the outcome of the change. It is important to engage faculty as sources as knowledge to be shared. Faculty empowerment, involvement, and commitment are key factors for the most favorable outcome. This can be accomplished through allowing each faculty member to be responsible for their own course or project, encouraging a bottom-up approach, a working group 
of ambassadors and resource group, and communication. Positive communication has occurred through seminars and round tables on SDE, workshops, conferences, funding for projects, publication possibilities staff development initiatives, and both internal and external communications (Verhulst \& Lambrechts, 2015, Holmberg et al., 2008). Additionally, these interactive approaches help to create curiosity and give importance to SDE contributions (Holmberg et al., 2008). Ambassadors and resource groups provide internal positive examples and support for change implementation. This active group of SDE teachers should be used to motivate and illustrate the changes needed and help continue a prolonged effort of motivating and coaching the lecturers to encourage tapping and expanding upon faculty's existing knowledge.

Providing educational resources and examples of successful SDE integration to instructors will help to provide assurance in their ability and security that they are important to the curriculum. In France, PACT 2D is a regional SDE collaboration project, in which part of the outcome is providing resources, such as integration techniques, how to utilize community resources, and classroom management (Anand et al., 2015), to participating HEIs. Soria et al. (2013) suggest using the following documents in order to develop a reference guideline for successful SDE integration: "Earth Charter Initiative, Spanish Environmental Education Guidebook, The Hannover Call, Agenda 21, and Royal Academy of Engineering Report on SDE" (p. 74). Additionally, documenting progress of the program will help other programs and HEIs with developing guidelines and resources for implementation by providing examples of success (Holmberg et al., 2008). When faculty feels supported, both professionally and educationally, their confidence in their own abilities increases and as a result are able to teach more effectively.

\section{Conclusion}

With our department curriculum redesign, it seems the perfect time to also integrate SDE; especially as a complete PBL environment will be introduced. The faculty is already heavily involved in the change process: identifying faculty strengths, analyzing current curriculum, and establishing learning objectives and outcomes. While this process is still ongoing, change management is still needed. Implementing any change within an organization can be challenging, however, with a strongly developed implementation strategy SDE can be incorporated with minimal setbacks. First identifying desired student learning objectives is essential to developing course and curriculum objectives. These objectives include both "hard" and "soft" skills, such as construction and environmental knowledge with application through critical thinking. Analysis of the existing curriculum and pedagogy identifies existing SDE and opportunities for vertical and horizontal integration. Active learning through PBL is the best application for learning SD within construction education courses. Learning from other institutions' challenges and successes is crucial to a seamless integration. Most notably, support of faculty in order to counteract resistance is key to success. Providing instructors with educational and implantation-related resources helps to provide relevance and positive associations with SDE integration. The progress of SDE implementation depends upon the program's or intuition's ability develop a plan that keeps open lines of communication as a source of support for faculty in order to proactively address any challenges of SDE implementation. 
Most research has focused on generalized preparation of soft skills required for sustainability, relying on the institution to know how to teach soft and technical skills and knowledge which are needed for sustainable construction. Institutions and organizations in Europe provide specific references for this, however, U.S. is lacking these resources. The LEED (Leadership in Energy and Environmental Design) building rating system provides some technical guidelines, but not necessarily exact paths to success. Consequently, the guidelines are created for any discipline involved in designing and constructing a building, not just construction managers, thus guidelines specifically focused for construction managers is needed. Further, specific technical guidelines towards a specialization, such as electrical, demolition, or healthcare, would help to provide more depth for the students interested in these areas of construction. 


\section{Reference List}

Anand, C. K., Bisaillon, V., Webster, A., \& Amor, B. (2015). Integration of sustainable development in higher education - A regional initiative in Quebec (Canada). Journal of Cleaner Production, 108, 916-923. http://doi.org/10.1016/j.jclepro.2015.06.134

Brncich, A., Shane, J. S., Strong, K. C., \& Passe, U. (2011). Using integrated student teams to advance education in sustainable design and construction. International Journal of Construction Education and Research, 7(1), 22-40. http://doi.org/10.1080/15578771.2010.512034

Ceulemans, K., Molderez, I., \& Van Liedekerke, L. (2015). Sustainability reporting in higher education: A comprehensive review of the recent literature and paths for further research. Journal of Cleaner Production, 106, 127-143. http://doi.org/10.1016/j.jclepro.2014.09.052

Dobson, H. E., \& Tomkinson, C. B. (2012). Creating sustainable development change agents through problem-based learning Designing appropriate student PBL projects. International Journal of Sustainability in Higher Education International Journal of Sustainability in Higher Education Iss International Journal of Sustainability in Higher Education Iss International Journal of Sustainability in Higher Education, 13(3), 431-449. http://doi.org/10.1108/14676371211242571

El-adaway, I., Pierrakos, O., \& Truax, D. (2015). Sustainable Construction Education Using Problem-Based Learning and Service Learning Pedagogies. Journal of Professional Issues in Engineering Education and Practice, 141(1), 05014002. http://doi.org/10.1061/(ASCE)EI.1943-5541.0000208

Holmberg, J., Svanström, M., Peet, D.-J., Mulder, K., Ferrer-Balas, D., \& Segalàs, J. (2008). Embedding sustainability in higher education through interaction with lecturers: Case studies from three European technical universities. European Journal of Engineering Education, 33(3), 271-282. http://doi.org/10.1080/03043790802088491

Jawahir, I. S., Rouch, K. E., Dillon, O. W., Holloway, L., \& Hall, a. (2007). Design for Sustainability ( DFS ): New Challenges in Developing and Implementing a Curriculum for Next Generation Design and Manufacturing Engineers. International Journal of Engineering Education, 23(6), 1053-1064.

Lozano, R., Ceulemans, K., Alonso-Almeida, M., Huisingh, D., Lozano, F. J., Waas, T., ... Hugé, J. (2015). A review of commitment and implementation of sustainable development in higher education: Results from a worldwide survey. Journal of Cleaner Production, 108, 1-18. http://doi.org/10.1016/j.jclepro.2014.09.048

Lozano, R., Ceulemans, K., \& Scarff Seatter, C. (2015). Teaching organisational change management for sustainability: Designing and delivering a course at the University of Leeds to better prepare future sustainability change agents. Journal of Cleaner Production, 106, 205-215. http://doi.org/10.1016/j.jclepro.2014.03.031

Manoliadis, O. (2009). Education for Sustainability: Experiences from Greece. Journal of Professional Issues in Engineering Education and Practice, 135(2), 70-74. http://doi.org/10.1061/(asce)1052-3928(2009)135:2(70) 
Sewilam, H., McCormack, O., Mader, M., \& Abdel Raouf, M. (2015). Introducing education for sustainable development into Egyptian schools. Environment, Development and Sustainability, 17(2), 221-238. http://doi.org/10.1007/s10668-014-9597-7

Soria, B. R., Bella, J. M. P., Hernández, J. D., Suñén, E. C., \& Díaz, Juan, J. del C. (2013). 1wEducation for Sustainable Development : Methodology and Application within a Construction Course. Journal of Professional Issues in Engineering Education Practice, 139(January), 72-79. http://doi.org/10.1061/(ASCE)EI.1943-5541.0000118.

Sullivan, J. G. \& Walters, R. (2013). Integrating Sustainability Curriculum into Construction Education: A Progress Report. Journal Of Sustainability Education, 92-100.

Valdes-vasquez, R. \& Clevenger, M. C. (2015). Piloting Collaborative Learning Activities in a Sustainable Construction Class. International Journal of Construction Education and Research, 8771(January), 1-18. http://doi.org/10.1080/15578771.2014.990122

Verhulst, E., \& Lambrechts, W. (2015). Fostering the incorporation of sustainable development in higher education. Lessons learned from a change management perspective. Journal of Cleaner Production, 106, 189-204. http://doi.org/10.1016/j.jclepro.2014.09.049

Wang, Y. (2009). Sustainability in Construction Education. Journal of Professional Issues in Engineering Education and Practice, 135(January), 21-30. http://doi.org/10.1061/(ASCE)1052-3928(2009)135:1(21)

Watson, M. K., Noyes, C., \& Rodgers, M. O. (2013). Student Perceptions of Sustainability Education in Civil and Environmental Engineering at the Georgia Institute of Technology. Journal of Professional Issues in Engineering Education and Practice, 139(3), 235-243. http://doi.org/10.1061/(ASCE)EI.1943-5541

WCED. (1992). Report of the World Commission on Environment and Development: Agenda 21, Chapter 36. http://www.un-documents.net/a21-36.htm

WCED. (1987). Report of the World Commission on Environment and Development: Our Common Future Acronyms and Note on Terminology Chairman's Foreword. Retrieved from www.un-documents.net/our-common-future.pdf

Wolcott, M., Brown, S., King, M., Ascher-Barnstone, D., Beyreuther, T., \& Olsen, K. (2011). Model for Faculty, Student, and Practitioner Development in Sustainability Engineering through an Integrated Design Experience. Journal of Professional Issues in Engineering Education and Practice, 137(April 2011), 94-101. http://doi.org/10.1061/(ASCE)EI.19435541.0000058

Yasin, R. M., \& Rahman, S. (2011). Problem Oriented Project Based Learning (POPBL) in promoting Education for Sustainable Development. Procedia - Social and Behavioral Sciences, 15, 289-293. http://doi.org/10.1016/j.sbspro.2011.03.088 